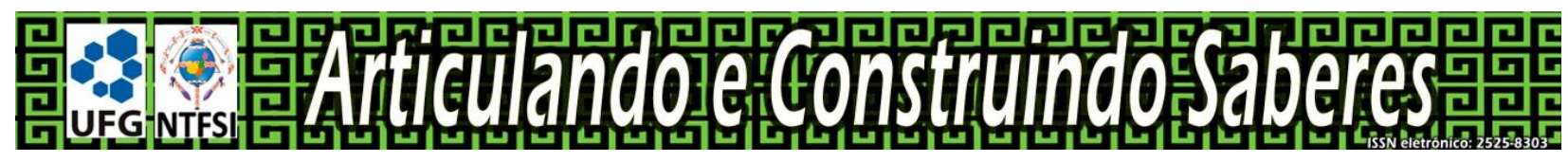

DOI: $10.5216 /$ racs.v4.59216

\title{
Pueblos originarios: mismo horizonte Mexico y Brasil
}

Catalina Cano Yáñez ${ }^{1}$

\section{RESUMEN}

Este texto trata del intercambio de experiencias entre educadores indigenas de Oaxaca, Puebla, Chiapas y Michoacán, y también con educadores indigenas de Roraima/Brasil. Estas experiencias pedagógicas, en sus distintos contextos, toman como base el Método Inductivo Intercultural (MII) y buscan crear prácticas de resistencia y de valorización de los modos propios de existir.

PALABRAS-CLAVE: Calendario socionatural. Método Inductivo Intercultural (MII). Interculturalidad.

\section{Povos originários: mesmo horizonte México e Brasil}

\section{RESUMO}

Este texto trata da troca de experiências entre educadores indígenas de Oaxaca, Puebla, Chiapas e Michoacán, e também com educadores indígenas de Roraima/Brasil. Todas estas experiências pedagógicas, em seus distintos contextos, tomam como base o Método Indutivo Intercultural (MII) e buscam criar práticas de resistência e de valorização dos modos próprios de existir.

Palavras-chave: Calendário socionatural. Método Indutivo Intercultural (MII). Interculturalidade.

Vivir el intercambio de experiencias fue muy gratificante y compartir el proyecto de Milpas Educativas con el método inductivo intercultural con los compañeros educadores de Oaxaca, Puebla, Chiapas y Michoacán, representando a México con los maestros de Boa Vista, Roraima Brasil, escuchando sus procesos de investigación para tener un calendario sociocultural de sus pueblos. Desde la teoría que ambos países estamos trabajando hacía un mismo sentir,

\footnotetext{
1 Maestra Náhuatl de Puebla. Povo Náhuatl. Cidade Trancas, Zoquitlan, Estado de Puebla, México. E-mail: articulandoeconstruindosaberes@,gmail.com.
} 
sustentado en Jorge Gashé con el Método Inductivo intercultural, el camino que llevamos en México con las Milpas educativas desde la praxis con el acompañamiento de la Dra. Maria Bertely Busquets, dentro de las escuelas con las Milpas Educativas, con las actividades fue como completar el trabajo entre ambo países, pero la reflexión surgió desde el reto de comunicase entre el idioma portugués de Brasil y español en México.

El sentir se dio más a través de la praxis con la actividad de la elaboración de la Damurida (caldo de pescado) comida de la comunidad indígena de Malacacheta, lugar donde estuvimos involucrados en este hacer, de donde son originarios los hermanos Macuxi y a través de esta actividad cultural podemos aprender haciendo, pero también reflexione la importancia del dialogo en lengua indígena desde nuestros pueblos, los aprendizajes se sitúa aún más significativos, entre profesores, padres-madres de familia y alumnos, en ese hacer pero también en el hablar, involucrar la lengua indígena como un dialogo natural para el interaprendizaje entre todos.

El ser Macuxi y Wapixana en Brasil, el ser nahuatl, tzeltal, tzotzil y purépecha desde México con más sentido de pertenencia étnica en algunas experiencias, fue una coincidencia importante entre educadores indígenas que viven este proceso. El trabajar casa adentro entre profesores indígenas, permite trabajar la interculturalidad desde lo propio hasta la escuela, la cual no sucede en su mayoría de las escuelas, pues suelen dejar fuera lo que hay en el contexto cultural fue otra similitud entre ambos países aun cuando la diferencia es que los compañeros de Brasil son rigurosos en las investigaciones de una forma más Vygotskiana con sus presentaciones académicas. En la presentación de sus calendarios socionaturales, se comprende por el proceso de académico que llevan a cabo y se interaprenden. En México para tener cuidado este proceso teórico desde nuestro hacer, pero también los compañeros de Brasil complementan con la praxis político pedagógico que estamos trabajando en México con las Milpas Educativas, donde se involucra el territorio más propiamente hasta llegar a la parte de la escuela. El interaprendizaje fue aprender desde nuestras respectivas fortalezas entre ambos países.

Las luchas sociales de una reivindicación de nuestros hermanos originarios desde la resistencia que ha llevado Chiapas y por otro lado los hermanos Macuxi, logre entender el contexto político donde en su momento lo comentó Gashe, como política capitalista, ·desde Gashé (2004)“'la naturaleza a volver los ricos más ricos, y los pobres todavía más pobres - y más furiosos." Entiendo el contexto mejor desde la visión de Chiapas y de Brasil, por otro lado, 
reflexiono en el mismo sentir de concepto de dominación/sumisión involucradas como políticas similares desde la desigualdad en políticas que solo benefician a los de arriba, donde los sujetos dominados y sumisos son exactamente los mismos, y parecería que es el mismo patrón entre México y Brasil.

Cuando escuché la voz de los hermanos Macuxi hasta el punto de conmoverse, entiendo su sentir desde mi experiencia del vivir en una ambivalencia, y lo recalca Gashe (2004) “ $L a$ praxis de resistencia, a la cual nos referimos antes, con todo su espesor humano, es valorada positivamente en la intimidad de la persona indígena y cuando convive con sus congéneres; pero sobre ella pesa la dominación con su negatividad y desprecio en el marco más amplio de la sociedad nacional y en la ciudad", y recuerdo mi experiencia desde la pertenencia de la identidad como recuperación del maestro indígena desde los diplomados de la "Explicitación y sistematización del conocimiento indígena".

En el primer proceso de explicitar lo describo como doloroso pero también de felicidad, pues como recuperas algo que perdiste en un proceso lento, pues es sanar de adentro y proyectar afuera esa felicidad, pero el primer paso es la sanación desde tu interior, a través de mirar esa historia de conquista en la cual han sido lastimados nuestros hermanos, y en la cual eres el resultado y desde esta perspectiva entiendo a los hermanos originarios y la parte donde luchan por revalorar lo que desde siempre es suyo, asimismo como es la lucha social, política y cultural, que se han enfrentado con los de arriba, y como la líder indígena Edite Andrade, está consciente que algunos maestros indígenas aun viven en esa ambivalencia, pero están luchando también en un trabajo que es difícil pero lo hacen constante por recuperar lo suyo, a través de esa educación intercultural que ha entrado a la escuela, en un sentido amplio.

Desde las actividades y valores étnicos de los pueblos originarios, algo que aunque se vislumbra desde esa educación de lo no propio, a la recuperación de lo propio, y que les ha costado a los maestros indígenas involucrar realmente la sabiduría de los pueblos originarios dentro de la escuela para México y con la resistencia, los maestros de Chiapas han dado catedra.

De esta manera concluyo que el proceso respecto a la resistencia hacia lo propio, lo enmarco en dos procesos bien dirigidos, desde los iniciadores en Chiapas, México, desde la UNEM con la praxis y que nos han dado catedra educadores de Chiapas con la autonomía de sus pueblos hacia ese sentir de revaloración de lo propio en educación intercultural, y en el mismo sentir, desde académicos Jorge Gashé y Dra. María Bertely Busquets de teorizar lo que hacen 
los pueblos originarios y comprender que realmente importa pues lo sostienen desde el buen vivir, en la cual observé en este sentido las propuestas académicas de los hermanos de Brasil, y así vislumbran a México desde el enfoque del Método Inductivo intercultural en un sentido teórico, pero que en ese proceso ansían vivenciar esa actividades desde la escuela.

\section{Bibliografia citada}

Gashe, J. La motivación política de la educación intercultural indígena y sus exigencias pedagógicas ¿Hasta dónde abarca la interculturalidad? Équipe de Recherche en Ethnologie Amérindienne, Centre National de la Recherche Scientifique, Villejuif (Francia) e Instituto de Investigaciones de la Amazonía Peruana, Iquitos (Perú). 2004.

Submetido em 22 de junho de 2019.

Aceito em 08 de agosto de 2019.

Publicado em 08 de agosto de 2019. 